\title{
Heterogeneous environmental regulation and industrial structure transformation and upgrading: Evidence from China
}

Lianghu Wang ( 230208754@seu.edu.cn )

Southeast University https://orcid.org/0000-0002-9059-1777

Zhao Wang

Southwest University

Yatian Ma

Southwest University

\section{Research Article}

Keywords: Heterogeneous environmental regulations, Industrial structure transformation and upgrading, Market incentive environmental regulation, Command-controlled environmental regulation, Voluntary public participation environmental regulation

Posted Date: April 19th, 2021

DOl: https://doi.org/10.21203/rs.3.rs-382490/v1

License: (c) (i) This work is licensed under a Creative Commons Attribution 4.0 International License. Read Full License

Version of Record: A version of this preprint was published at Environmental Science and Pollution Research on September 30th, 2021. See the published version at https://doi.org/10.1007/s11356-02116591-7. 


\title{
2 transformation and upgrading: Evidence from China
}

\author{
Lianghu Wang a, Zhao Wang ${ }^{\text {b }}$, and Yatian Ma ${ }^{\mathrm{b}}$ \\ ${ }^{a}$ School of Economics and Management, Southeast University, Nanjing 211189, China; \\ ${ }^{\mathrm{b}}$ School of Economics and Management, Southwest University, Chongqing 400715, China; \\ * Correspondence: 230208754@ @eu.edu.cn (L. Wang); Tel.: +86-188-7507-7035 \\ Received: date; Accepted: date; Published: date
}

\begin{abstract}
There are obvious differences between different types of environmental regulations, which are manifested in different environmental protection tendencies and goals, and there are also significant differences in policy implementation. Therefore, it is an urgent empirical problem to quantitatively evaluate the impact of heterogeneous environmental regulations on the transformation and upgrading of industrial structure. Based on this, this paper empirically tests the impact of heterogeneous environmental regulations on the transformation and upgrading of industrial structure on the basis of measuring the level of industrial structure transformation and upgrading. The results show that the transformation and upgrading level of China's industrial structure increased year by year from 2000 to 2017. The three types of environmental regulatory measures have effectively promoted the transformation and upgrading of the industrial structure, and the market incentive environmental regulation (MER) has a significantly higher role in the advancement of the industrial structure than the command-controlled environmental regulation (CER) and the voluntary public participation environmental regulation (VER). The three types of environmental regulations have gradually highlighted the role of environmental regulations in promoting the transformation and upgrading of industrial structure with the improvement of the level of regional economic development. In the mechanism test, it is found that technological innovation has partial mediating effect in the process of CER affecting the transformation and upgrading of industrial structure, MER and public VER have complete mediating effect, while FDI has only partial mediating effect in the process of three types of environmental regulation affecting the transformation and upgrading of industrial structure.

Keywords: Heterogeneous environmental regulations; Industrial structure transformation and upgrading; Market incentive environmental regulation; Command-controlled environmental regulation; Voluntary public participation environmental regulation
\end{abstract}

\section{Introduction}

After more than 40 years of reform and opening up, China's economic growth has created a miracle in the history of world economic development. According to data from the National Bureau of Statistics, China's GDP grew at an average annual rate of $9.3 \%$ from 1979 to 2019 , and its average annual contribution to world economic growth was about $18 \%$. However, in the early stage, China's excessive reliance on extensive development with high investment, high energy consumption, and high pollution caused excessive use of resources and severe environmental damage, which became the main obstacle to economic growth ( $\mathrm{Lu}, 2017$; Liao, 2018), and resources increasingly depleted and deteriorating ecological environment (Dai, 2015). Therefore, coordinating the relationship between ecological health and economic growth is the key to implementing sustainable development strategies (Abu Seman et al., 2019). The "2018 Global Environmental Performance Index (EPI) Report" released by Yale University and others pointed out that among the 180 countries participating in the evaluation, China ranked 120, which shows that China's environment is in urgent need of improvement. China's economy has reached a critical moment when it has to change its economic development mode, that is, from a stage of rapid growth to a stage of high-quality development. The transformation and upgrading of industrial structure is an important way to coordinate sustainable economic development and environmental protection. The characteristic of industrial structure upgrading is that production factors enter high-value-added, highefficiency and low-consumption industries from low-value-added, low-efficiency and high-consumption 
industrial chain links. The process of chain links is one of the key drivers of economic growth. (Pipkin and Fuentes, 2017; Zhu et al., 2019). Therefore, in order to alleviate the downward pressure on the economy, the Chinese government is seeking to transform the economic development mode, optimize the industrial economic structure, increase total factor productivity, and promote the national economy. (Hu et al., 2020; Guo et al., 2020). The transformation of industrial structure can not only increase the proportion of technology-intensive and knowledge-intensive industries, promote technological progress, and support emerging industries, but also reduce the proportion of high-polluting and high-energyconsuming industries, encouraging environmental technology research and development and investment in cleaner production equipment, and improve the level of cleaner production from the root cause.

However, the current problem of irrational and unbalanced industrial structure in China has gradually emerged (Heinrich and Dai, 2016), which has attracted the attention of the government. In the "13th Five-Year" development plan outline, it is clearly proposed to promote the transformation and upgrading of the industrial structure. The report of the 19th national Congress of the Communist Party of China is relayed to the goal of promoting the development of industrial structure to the high end of global value chain. The current transformation and upgrading of China's industrial structure mainly relies on the guidance and intervention of industrial policies, which has a relatively serious color of planned economy, resulting in a lack of internal incentives for policy effects. To transform the mode of economic development and lead the economy to high-quality development. The Chinese government has chosen a path that can both improve the environment and promote sustainable economic development. For this reason, it has issued a number of environmental policies to deal with environmental problems in the process of industrial development. Among them, environmental regulation is an important measure for environmental protection at this stage. The implementation of environmental regulation policies increases the internal cost of enterprises, prompts enterprises to transform production methods, produces an effect of survival of the fittest, and ultimately drives the transformation and upgrading of industrial structure (Ramanathan et al., 2010; Ahmed et al., 2016). With the advancement of environmental regulatory policies, China's industrial structure has undergone major changes. In 2015, the tertiary industry's contribution to China's GDP exceeded 50\% for the first time (Yu ang Wang, 2020). In 2019, the three major industries accounted for $7.1 \%, 39 \%$ and $53.9 \%$ of GDP.

There are obvious differences between different types of environmental regulations, which are reflected in different environmental protection tendencies and goals, and there are also significant differences in policy implementation, so the impact on industrial structure transformation and upgrading will also be different. The Chinese government has gradually established a command and control type, market incentive type, and voluntary public participation type "three-dimensional one" environmental policy tool system. The heterogeneity between the three will directly affect the cost constraints of industrial structure transformation and upgrading, and thus affect "Porter effect" and "Compliance cost effect" in environmental regulation. Ignoring the heterogeneity of environmental regulations or conducting a total-level analysis of environmental regulations can easily lead to deviations in the assessment of the effects of environmental regulations and policies (Li, 2020). Therefore, the research on environmental regulations should not only involve the strength of environmental regulations, but also include the reasonable mix and use of heterogeneous environmental regulatory policy tools. Based on this, this paper studies the impact of heterogeneous environmental regulations on the transformation and upgrading of industrial structure based on different types of environmental regulation perspectives. To explore whether China's environmental regulations promote the transformation and upgrading of the industrial structure while tackling environmental pollution? That is, can we achieve a win-win situation between environmental protection and industrial structure transformation and upgrading?

The rest of this paper is organized as follows. The second part is a literature review. The third part is research design. The fourth part is the discussion of the empirical results, and the final part is the summary of the research conclusions and policy implications.

\section{Literature review}

Scholars focus on "Porter Hypothesis" and "Pollution Haven Hypothesis", and research shows that environmental regulation policies can affect regional industrial structure in various ways (Gouldson et al., 2014; Wang et al., 2019; Zhang et al ., 2019). According to the existing relevant industrial economic 
theories, strict environmental regulations increase the production costs of enterprises, thus having a certain impact on the transformation and upgrading of industrial structure. However, due to different research perspectives, measurement methods or indicators, the research conclusions have not yet formed a consistent view, which are mainly divided into three situations: promotion, inhibition and uncertainty. First, regarding the "benefits" theory, it is believed that appropriate environmental regulations can induce enterprise innovation. Although enterprises may increase costs and reduce competitiveness in the short term, they are beneficial to the development of enterprises in the long run, thus promoting the transformation and upgrading of industrial structure, namely "Porter Hypothesis" (Porter, 1991; Porter, 1995; Keller and Levnson, 2002; Gurtoo and Antony, 2007). Some scholars have demonstrated the "Porter Hypothesis" from different premises (Cole et al., 2005; Ramanathan et al., 2010; Hou et al., 2018; Yu ang Wang, 2020), For example, Burton et al. (2011) studied the pulp and paper industry through environmental regulation factors, and concluded that environmental regulation has a significant role in promoting the growth of such enterprises and significantly improving the level of structural optimization of the industry. Liu et al. (2016) constructed a theoretical model of the impact of environmental regulation on the upgrading of industrial structure. They pointed out that if the technical effect of environmental regulation is higher than the distortion effect of resource allocation, environmental regulation will promote the transformation and upgrading of industrial structure. Shehabi (2020) studied the impact of energy subsidy reform on Kuwait's economic diversification. The results show that the implementation of environmental supervision policies can reduce the excessive dependence of economic development on resources and the environment, promote the diversified development of the industrial structure of resource-based countries, and reverse the disease problem in the Netherlands.

The second is that the "unfavorable theory" means that increasing the intensity of environmental regulations will increase the company's "compliance cost", weaken its market price advantage, and then put the company at a disadvantage in market competition, and ultimately inhibit the transformation and upgrading of the industrial structure (Jaffe and Palmer, 1997). Specifically, in order to circumvent environmental regulations or reduce environmental costs, regional differences in environmental standards or environmental regulations will encourage polluting companies to transfer, thereby inhibiting the adjustment of the industrial structure of the region or the country, that is, the "Pollution Refuge" effect. (Millimet et al., 2016; Solarin et al., 2017). Kheder and Zugravu (2012) studied the impact of environmental regulations on the site selection of French manufacturing and found that there was a "pollution paradise effect" in the process of corporate site selection. Millimet et al. (2009) believes that environmental regulations have increased the production costs of enterprises, reduced production efficiency and profits, and affected the industry structure through enterprise entry or exit, production scale adjustment and resource reallocation. Alpay et al. (2002) found that environmental regulation is a negative hindrance on the food processing industry in the United States.

Third, the impact of environmental regulations on the transformation and upgrading of industrial structure is uncertain, that is, the relationship between environmental regulations and industrial structure transformation and upgrading is nonlinear (Zhou et al., 2017; Zhao et al., 2018; Chen and Qian, 2020;). Yuan et al. (2014) used panel data from 30 provinces in China from 1999 to 2011, and the study showed that the impact of environmental regulations on industrial structure adjustment was first restrained, followed by promotion, and then restrained. Tong et al. (2016) constructed a theoretical model of environmental regulation, factor input structure, and industrial industry transformation and upgrading. The study found that the impact of environmental regulation on industrial industry transformation and upgrading presents a J-shaped characteristic. Chen and Qian (2020) compared and analyzed the dual impact of different types of marine environmental regulations on the upgrading of manufacturing industry structure and the transfer of polluting industries based on the panel data of China's coastal areas from 2004 to 2017. Research shows that various types of marine environmental remediation have a positive U-shaped relationship with the transfer of polluting industries and the upgrading of industrial structure.

With the increasingly serious environmental pollution corresponding to economic development, the cost of pollution control continues to increase. Over the past few decades, the environmental regulation thinking has developed from the end-point management level to the level of pollution prevention, ecological efficiency and product life cycle analysis (El-Zayat et al., 2006). Because of ignoring the 
heterogeneity of environmental regulations or conducting a total level analysis of environmental regulations, it is easy to bias the evaluation of the effects of environmental regulations and policies $(\mathrm{Li}$, 2020). Therefore, in the same period, most national environmental management systems have shifted from a single government-led environmental management to a multi-coordinated environmental governance (Taylor et al., 2013). Shen et al. (2019) used a threshold model to study the nonlinear dynamic effects of different types of environmental regulations on the environmental total factor productivity of the industrial sector from the perspective of heterogeneity, trying to determine the optimal intensity and tool combination of environmental regulations. The research results show that due to the existence of heterogeneous industries, different types of environmental regulations have a heterogeneous impact on the environmental total factor productivity of different industries. Due to the large differences in the level of economic development between regions in China, there may be differences in the "innovation compensation effect" and the "compliance cost effect" produced by environmental regulations, leading to differences in the impact of environmental regulations on the transformation and upgrading of regional industrial structures. Moreover, the transformation and upgrading of the industrial structure is mainly manifested in two aspects: the rationalization and advanced of the industrial structure. Only when environmental regulations simultaneously promote the rationalization and advancement of the industrial structure can the transformation and upgrading of the industrial structure be realized in a real sense. Based on this, first of all, this research measures the development level of China's industrial structure transformation and upgrading from two aspects, rationalization and advancement of the industrial structure. Secondly, based on the perspective of different types of environmental regulation, this paper uses panel data model and threshold model to study the impact of heterogeneous environmental regulation on the transformation and upgrading of industrial structure, and discusses the impact mechanism, so as to provide new empirical evidence for the relationship between environmental regulation and the transformation and upgrading of industrial structure.

\section{Research design}

\subsection{Model setting}

This paper mainly explores the relationship between heterogeneous environmental regulations and industrial structure transformation and upgrading. As the Chinese government has gradually established a command-and-control, market-incentive and voluntary public participation "three-dimensional one" environmental policy tool system. At the same time, considering that the three types of environmental regulations may directly have complementary possibilities, the three types of environmental regulation interaction items are introduced into the model to construct the following panel data model.

$$
\begin{gathered}
T L_{i t}=\alpha_{0}+\alpha_{1} C E R_{i t}+\alpha_{2} M E R_{i t}+\alpha_{3} P E R_{i t}+\alpha_{4} C E R_{i t} \times M E R_{i t} \times P E R_{i t}+\alpha_{5} X_{i t}+\xi_{i t} \\
E S_{i t}=\beta_{0}+\beta_{1} C E R_{i t}+\beta_{2} M E R_{i t}+\beta_{3} P E R_{i t}+\beta_{4} C E R_{i t} \times M E R_{i t} \times P E R_{i t}+\beta_{5} X_{i t}+\zeta_{i t}
\end{gathered}
$$

Where, $T L$ and $E S$ are industrial structure rationalization and advanced industrial structure, respectively, CER, MER, and PER represent command-control, market incentive, and voluntary public participation environmental regulations, $X$ is a controlled variable, and subscripts $\mathrm{i}$ and $\mathrm{t}$ represent province and time, $\xi_{i t}$ and $\zeta_{i t}$ represent residual items.

Taking into account the large differences in the level of economic development between regions in China, there may be differences in the "innovation compensation effect" and "compliance cost effect" produced by environmental regulations, leading to differences in the impact of environmental regulations on the transformation and upgrading of regional industrial structures. Furthermore, taking the level of regional economic development as the threshold, this paper uses the threshold model to study the impact of heterogeneous environmental regulation on the transformation and upgrading of industrial structure. In the past, most studies on the "threshold effect" used methods such as grouping experience and adding cross-terms. Grouping experience was restricted by the grouping criteria and could not accurately 
estimate the threshold value. Although the cross-term was added to the model to estimate the threshold value, it could not verify the correctness of the threshold. It was not until Hansen (1999) proposed the non-dynamic panel threshold regression modeling idea that it solved the accurate measurement of the "threshold effect". The choice of threshold variables can be determined exogenously by the theoretical model. The threshold regression model originally proposed by Hansen (1999) is as follows.

$$
\begin{aligned}
& y_{i}=x_{i}^{*} \beta_{1}+e_{i}, \quad q_{i} \leq \gamma \\
& y_{i}=x_{i}^{*} \beta_{2}+e_{i}, \quad q_{i}>\gamma
\end{aligned}
$$

Where, $y_{i}$ is the explained variable, $x_{i}$ is the $p \times 1$ order explanatory variable vector, and $q_{i}$ is the threshold variable. The threshold variable $q_{i}$ serves to divide the sample into different groups, and the regression coefficients in the model are determined based on whether the threshold variable is greater than or less than a certain threshold value.

Define the dummy variable $d_{i}(\gamma)=\left(q_{i} \leq \gamma\right)$, where $I(\bullet)$ is the indicator function, that is, for $q_{i} \leq \gamma, I(\bullet)=0$, otherwise $I(\bullet)=0$. Therefore, the above model can be transformed into the following model.

$$
y_{i}=x_{i}^{*} \beta+x_{i}^{*} d_{i}(\gamma) \theta+e_{i}
$$

Where, $\beta=\beta_{2} ; \quad \theta=\beta_{1}-\beta_{2}$ 。

This paper draws on the threshold regression model of Hansen (1999) and establishes a single threshold regression model as follows.

$$
\begin{array}{rl}
T L_{i t}=a_{11} C E R_{i t} & I\left(E D \leq \gamma_{1}\right)+a_{12} C E R_{i t} I\left(E D>\gamma_{1}\right)+a_{21} M E R_{i t} I\left(E D \leq \gamma_{2}\right) \\
& +a_{22} M E R_{i t} I\left(E D>\gamma_{2}\right)+a_{31} P E R_{i t} I\left(E D \leq \gamma_{3}\right)+a_{32} P E R_{i t} I\left(E D>\gamma_{3}\right) \\
& +a_{4} C E R_{i t} \times M E R_{i t} \times P E R_{i t}+a_{5} X_{i t}+\varepsilon_{i t} \\
& \\
E S_{i t}=\beta_{11} C E R_{i t} & I\left(E D \leq \gamma_{1}\right)+\beta_{12} C E R_{i t} I\left(E D>\gamma_{1}\right)+\beta_{21} M E R_{i t} I\left(E D \leq \gamma_{2}\right) \\
& +\beta_{22} M E R_{i t} I\left(E D>\gamma_{2}\right)+\beta_{31} P E R_{i t} I\left(E D \leq \gamma_{3}\right)+\beta_{32} P E R_{i t} I\left(E D>\gamma_{3}\right) \\
& +\beta_{4} C E R_{i t} \times M E R_{i t} \times P E R_{i t}+\beta_{5} X_{i t}+\varepsilon_{i t}
\end{array}
$$

(6) and (7) where ED is the threshold variable, which represents the level of regional economic development, $\gamma_{1}, \gamma_{2}$, and $\gamma_{3}$ are the threshold values, and the meaning of other variables is consistent with the benchmark model.

\subsection{Variable description}

\subsubsection{Dependent variable}

Industrial structure refers to the composition of various industrial sectors and within each industrial part in the national economy. The transformation and upgrading of industrial structure is the process of industrial structure changing from a low-level form to a high-level form (Ernst, 1998). The dependent variable of this paper is the transformation and upgrading of industrial structure, which is mainly measured from two dimensions of industrial structure rationalization and industrial structure advancement. The rationalization of industrial structure not only reflects the ability of inter-industry structural transformation, but also reflects the effective use of resources. It is a measure of the degree of coordination between factor input and industry. Existing studies generally use the degree of structural deviation to measure the level of rationalization of industrial structure, but because this method ignores the different roles of different industries in economic development, the measurement results may be biased. Therefore, this paper selects the Theil Index, which takes into account the deviation of the output value and employment structure of each industry, and the difference in the economic status of each industry, as a measure of the rationalization of the regional industrial structure. The specific calculation formula is as follows. 


$$
T L=\sum_{m=1}^{3}\left(\frac{Y_{m}}{Y}\right) \ln \left(\frac{Y_{m}}{L_{m}} / \frac{Y}{L}\right), \quad m=1,2,3
$$

Where, TL stands for Theil Index, Y stands for output value, L stands for employment, and m stands for three major industries. When $\mathrm{TL}=0$, the economy is in an equilibrium state. The larger the $\mathrm{TL}$ value, the more easily the economic development deviates from the equilibrium state and the more unreasonable the industrial structure.

The advancement of industrial structure is an important part of the transformation and upgrading of industrial structure. In general literature, the advancement of industrial structure is defined as the increase in the proportion of non-agricultural output value, but this method cannot accurately reflect the nature of industrial structure evolution. The advancement of industrial structure involves the evolution of industrial proportional relations and the improvement of labor productivity (Liu et al., 2008). Therefore, referring to the method of Liu et al. (2008), the product of the inter-industry proportional relationship and labor productivity is used as a measure of advanced industrial structure. Calculated as follows.

$$
E S=\sum_{m=1}^{3} \frac{Y_{m}}{Y} \times L P_{m}, \quad m=1,2,3
$$

Where, ES stands for advanced industrial structure, and LP stands for labor productivity, which is calculated by using the ratio of regional industrial added value to the number of employees at the end of the same period. The larger the ES value, the higher the degree of advanced industrial structure.

\subsubsection{Key independent variables}

Command controlled environmental regulation (CER) mainly refers to the government's adoption of compulsory environmental regulations to intervene in corporate pollution discharge activities to achieve the external goal of reducing environmental pollution. Refer to the practice of Wu et al. (2020) to select the employment index of regional environmental agencies instead. Market incentive environmental regulation (MER) is stimulated by economic interests and influences the environmental behavior of the parties through market forces, mainly including sewage charges, subsidies, taxes, etc. Among them, sewage charges are the earliest market-incentive environmental regulation tool. And the scope of implementation is wide, the time span is long, and it is more representative than policies such as emissions trading and subsidies. Therefore, this paper draws on the practices of Levinson (1996) and Xie et al (2017) and uses pollution fees to characterize market incentive environmental regulations. Voluntary Public Participation Environmental Regulation (PER) is a non-statutory agreement established between enterprises, governments, or non-profit organizations, and the purpose of this agreement is to improve environmental quality or enable effective use of natural resources. Environmental proposals are an important form of public participation in environmental protection supervision, which reflect the people's attention to environmental issues. This paper uses environmental proposals to reflect public voluntary participation in environmental regulations.

\subsubsection{Threshold variable}

The regional development level (ED) situation determines the environment in which the industrial structure transformation and upgrading is located. Therefore, the regional economic development level is very important to the industrial structure transformation and upgrading. This paper uses per capita GDP as a measure of the regional economic development level, and takes it as a threshold variable.

\subsubsection{Control variables}

According to the existing research, some provincial characteristics are added as control variables in the regression analysis of the model to alleviate the bias of omitted variables as much as possible. Natural resource endowment (NR). Natural resource endowment not only reflects the resource constraints of various regions in the choice of industrial structure, but also reflects the principle of comparative advantage of economic development. For the measurement of natural resource endowment, this paper selects the sum of fixed asset investment of agriculture, forestry, animal husbandry, fishery and extractive industries as the proportion of the total fixed asset investment of the whole society to reflect the comprehensive endowment of natural resources in various regions to the greatest extent. Resident 
consumption (RC). It is generally believed that with the improvement of living standards, people will pay more attention to the quality of life, environment and other factors, which will have a compelling effect on the transformation and upgrading of the industrial structure. This paper uses the ratio of the consumption level of each region to the region's GDP to measure. Informatization (IT). Due to data limitations, this paper uses per capita post and telecommunications business to measure the level of informatization. Financial development level (FL). Levine (1997) believes that financial development is accompanied by economic development. With the continuous development of financial markets, the provision of financial services for economic entities has promoted the optimal allocation of resources, and has a certain role in promoting the transformation and upgrading of industrial structure. This paper draws on the common practice of existing literature and takes the proportion of the loan balance of each region in the total output value of the region at the end of the year as a measure of the level of financial development.

\subsection{Descriptive statistics of data sources and variables}

Due to the availability of data, this paper takes 30 provinces in China as the research object, and selects panel data from 2000 to 2017 . The data used in the empirical research are mainly derived from the China Statistical Yearbook, China Environmental Statistical Yearbook, China Environmental Yearbook, and the provincial-level statistical yearbooks. All nominal data are based on the year 2000 and are deflated by using the general production index and the consumer price index respectively. For a small part of missing data, it is estimated by trend fitting. Table 1 summarizes the data characteristics of each variable. At the same time, in order to solve the heteroscedasticity problem, the data processing mostly adopts the method of ratio or natural logarithm. See Table 1 for details.

Table 1 Descriptive statistics of variables

\begin{tabular}{cccccc}
\hline Variable & $\mathrm{N}$ & Mean & Max & Min & Std. Dev. \\
\hline$T L$ & 540 & 0.250 & 0.934 & 0.007 & 0.157 \\
$E S$ & 540 & 7.937 & 29.969 & 0.284 & 5.759 \\
$C E R$ & 540 & 7.859 & 10.000 & 4.000 & 1.004 \\
$M E R$ & 540 & 10.399 & 14.761 & 6.685 & 1.086 \\
$P E R$ & 540 & 4.879 & 7.000 & 0.000 & 1.080 \\
$E D$ & 540 & 2.886 & 12.906 & 0.124 & 2.429 \\
$N R$ & 540 & 0.068 & 0.326 & 0.000 & 0.057 \\
$R C$ & 540 & 0.363 & 0.750 & 0.107 & 0.079 \\
$I T$ & 540 & 0.139 & 0.699 & 0.012 & 0.107 \\
$F L$ & 540 & 0.998 & 5.332 & 0.182 & 0.463 \\
\hline
\end{tabular}

Based on the above methods, the degree of rationalization and advancement of the industrial structure of 30 regions in China from 2000 to 2017 was measured, and the average change trend was calculated. The details are shown in the figure. It can be seen from Figure 1 that, first of all, the Theil Index is in a downward trend as a whole, indicating that China's industrial structure configuration level is gradually increasing, and the industrial structure tends to be rationalized, but there is still a certain distance from the optimal level. Secondly, judging from the magnitude of the change in Theil Index, most years showed negative growth, especially after 2012 , the decline was large, and only a small increase in 2017. 


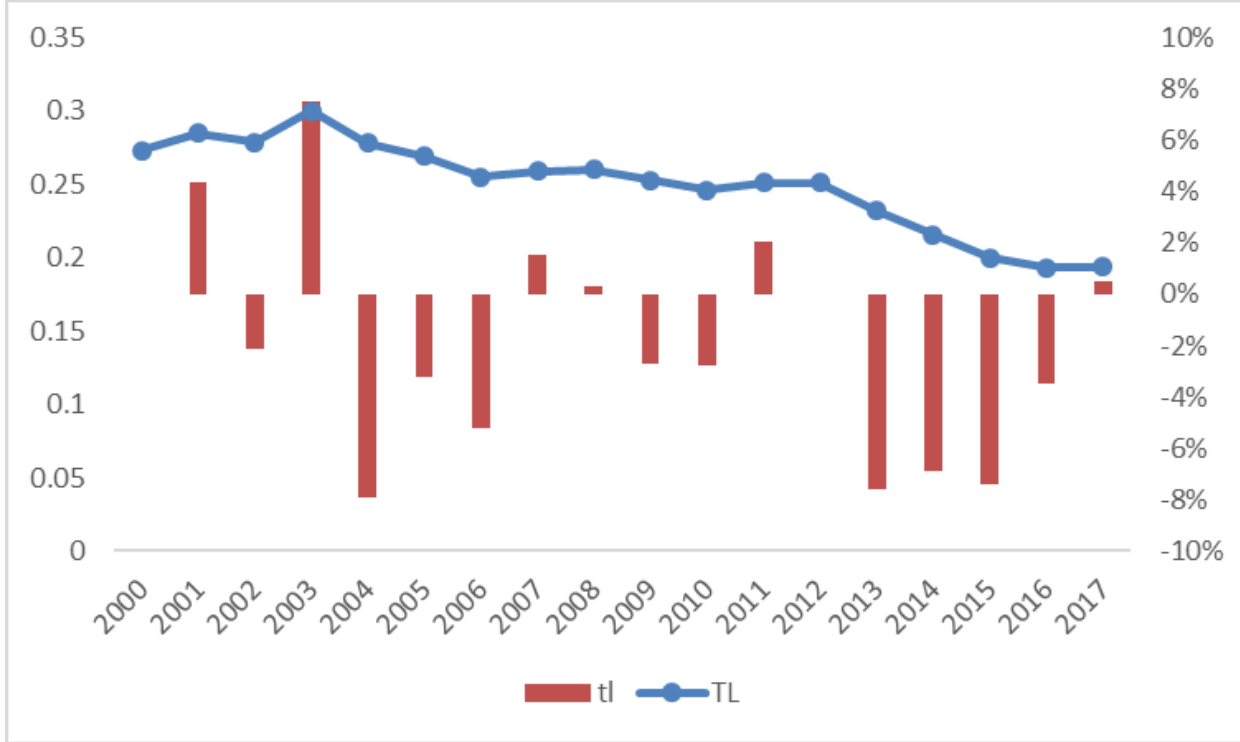

Fig. 1. The average Theil index and its change range from 2000 to 2017

Note: $\mathrm{tl}$ is the range of changes in the rationalization of the industrial structure. TL is the Theil Index.

It can be seen from Figure 2 that the upgrading degree of the industrial structure from 2000 to 2017 is constantly improving, which indicates that China's industrial structure is changing from the low-level form of "primary industry, secondary industry and tertiary industry" to the high-level form of "tertiary industry, secondary industry and primary industry". From the perspective of the growth rate of the advanced industrial structure, most years realized positive growth, only 2004 was negative growth, and the growth rate was relatively large in the eight years from 2005 to 2012. This shows that China's industrial structure has improved significantly during this period. In 2013 and the following years, the development speed of China's industrial advancement has slowed down, and the growth rate is about $4 \%$.

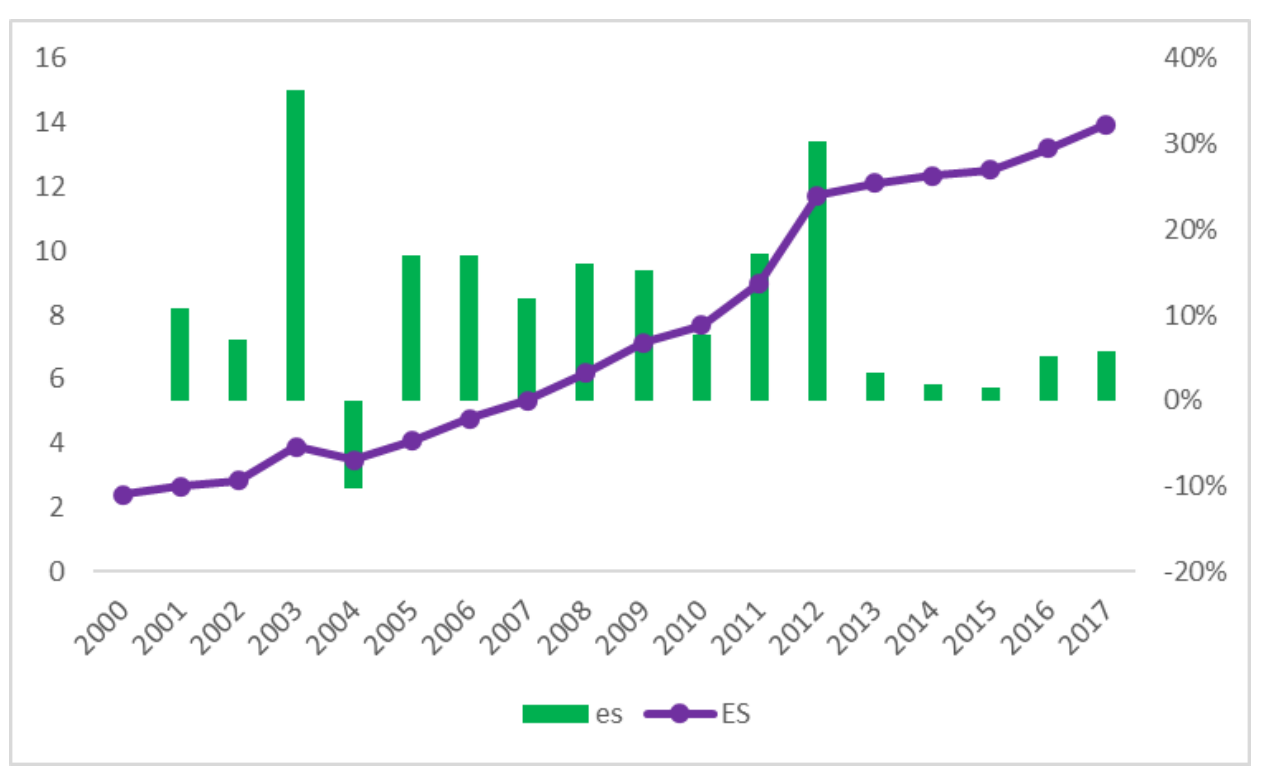

Fig. 2. Average industrial structure advancement and its change range from 2000 to 2017 Note: es is the range of changes in the advanced industrial structure; ES is the advanced industrial structure. 


\section{Empirical results}

\subsection{Benchmark regression}

Firstly, before panel data regression, the model needs to be tested with Hausman statistics to determine whether to use a random effects model or a fixed effects model. Secondly, in order to avoid the bias of the estimation results caused by the multicollinearity of the model, this paper adopts the stepwise regression method to perform regression estimation on the model. The results of Hausman test show that the fixed effects model is better than the random effects model, so the fixed effects model is selected. The regression results of the model are shown in Table 2 and Table 3. It can be seen from the regression results of the model that the overall model has passed the significance test of the $\mathrm{F}$ statistic, indicating that the measurement model is set reasonably. The following is a detailed analysis of the regression structure of the model with the rationalization of industrial structure and advanced industrial structure as dependent variables.

The model (1) in Table 2 does not include any control variables in the panel data model regression estimation. CER, MER and PER are all negative at the $1 \%$ significance level, which indicates that the three types of environmental regulation measures have effectively reduced the deviation degree of industrial structure, that is, improved the rationalization level of industrial structure. From the regression results of the three interaction terms, it does not have a positive effect on the rationalization of the industrial structure. The possible reason is that there are problems in the convergence of the three types of environmental regulations in China, and the three types of environmental regulations have not exerted the greatest effect. Models (3)-(6) gradually added control variables, and the key independent variables did not change significantly, indicating that the model estimation results have a certain degree of robustness. From the perspective of the regression coefficients of the control variables, the level of residential consumption, informatization and financial development has improved the rationalization level of the industrial structure at a significant level of $1 \%$. The transformation of residents' consumption structure has a certain negative effect on the rationalization of industries. In recent years, the income level of residents has been increasing year by year, and the consumption structure has been upgraded. In order to meet consumption needs, the industrial structure will inevitably change. The process of informatization contains the mechanism of rapid industrial development, which directly promotes the rationalization of industrial structure. With the improvement of the level of financial development, the provision of financial services for industrial development has promoted the optimal allocation of resources and reduced its financing costs, thereby conducive to the development of a rationalized industrial structure. The natural resource endowment is positively correlated with the Theil Index, but it has not passed the significance test, indicating that natural resource endowment has not played an effective role in the rationalization of industrial structure.

Table 3 reports the regression results of CER, MER and VER on the advanced measurement of industrial structure. Model (1) Panel data model regression estimation without any control variables, CER, MER, and PER are all positive at a significant level of $1 \%$, which indicates that the three types of environmental regulatory measures have effectively improved the advanced industrial structure Level. Moreover, the role of MER in the advancement of the industrial structure is significantly higher than the role of CER and VER. This shows that with the continuous improvement of China's market structure, environmental regulation policies based on market development will play a leading role in the transformation and upgrading of industrial structure. Similarly, the interaction terms of the three types of environmental regulations have a negative effect on the advancement of the industrial structure, which once again proves that the coordination of the three types of environmental regulations in China needs to be further optimized. From the perspective of the regression coefficients of the control variables, household consumption, informatization and financial development levels have increased the level of advanced industrial structure at a significant level of $1 \%$, while natural resource endowments are negatively correlated with the advanced industrial structure. There are related explanations in the previous paper, so I won't repeat them here. 
Table 2 Benchmark regression results (TL)

\begin{tabular}{|c|c|c|c|c|c|c|}
\hline Variable & (1) & (2) & (3) & (4) & (5) & (6) \\
\hline \multirow[t]{2}{*}{ CER } & $-0.027^{* * *}$ & $-0.036^{* * *}$ & $-0.037^{* * *}$ & $-0.042^{* * *}$ & $-0.034^{* * *}$ & $-0.024^{* *}$ \\
\hline & $(0.0087)$ & $(0.0127)$ & $(0.0127)$ & $(0.0126)$ & $(0.0125)$ & $(0.0121)$ \\
\hline \multirow[t]{2}{*}{$M E R$} & $-0.016^{* * *}$ & $-0.022^{* * *}$ & $-0.023^{* * *}$ & $-0.028^{* * *}$ & $-0.019^{* *}$ & $-0.013^{*}$ \\
\hline & $(0.0049)$ & $(0.0073)$ & $(0.0075)$ & $(0.0075)$ & $(0.0077)$ & $(0.0074)$ \\
\hline \multirow[t]{2}{*}{ PER } & $-0.015^{* * *}$ & $-0.031^{* *}$ & $-0.026^{* *}$ & $-0.035^{* *}$ & $-0.029^{*}$ & -0.020 \\
\hline & $(0.0039)$ & $(0.1548)$ & $(0.0155)$ & $(0.0153)$ & $(0.0151)$ & $(0.0146)$ \\
\hline \multirow[t]{2}{*}{ Inter } & & 0.059 & 0.058 & 0.072 & 0.055 & 0.039 \\
\hline & & $(0.0582)$ & $(0.0582)$ & $(0.0575)$ & $(0.0568)$ & $(0.0545)$ \\
\hline \multirow[t]{2}{*}{$N R$} & & & 0.073 & 0.037 & 0.087 & 0.023 \\
\hline & & & $(0.1023)$ & $(0.1012)$ & $(0.1003)$ & $(0.0977)$ \\
\hline \multirow[t]{2}{*}{$R C$} & & & & $-0.090^{* * *}$ & $-0.106^{* * *}$ & $-0.103^{* * *}$ \\
\hline & & & & $(0.0228)$ & $(0.0227)$ & $(0.0382)$ \\
\hline \multirow[t]{2}{*}{$I T$} & & & & & $-0.176^{* * *}$ & $-0.126^{* * *}$ \\
\hline & & & & & $(0.0423)$ & $(0.0412)$ \\
\hline \multirow[t]{2}{*}{$F L$} & & & & & & $-0.102^{* * *}$ \\
\hline & & & & & & $(0.0154)$ \\
\hline \multirow[t]{2}{*}{ _cons } & $0.708^{* * *}$ & $0.561^{* * *}$ & $0.574^{* * *}$ & $0.648^{* * *}$ & $0.594^{* * *}$ & $0.521^{* * *}$ \\
\hline & $(0.0723)$ & $(0.1616)$ & $(0.1627)$ & $(0.1615)$ & $(0.1595)$ & $(0.1534)$ \\
\hline \multirow[t]{2}{*}{ Hausman } & \multicolumn{6}{|c|}{20.26} \\
\hline & \multicolumn{6}{|c|}{$(0.0164)$} \\
\hline \multirow[t]{2}{*}{$F$} & 77.16 & 75.97 & 65.19 & 66.27 & 55.44 & 58.31 \\
\hline & $(0.0000)$ & $(0.0000)$ & $(0.0000)$ & $(0.0000)$ & $(0.0000)$ & $(0.0000)$ \\
\hline$N$ & 540 & 540 & 540 & 540 & 540 & 540 \\
\hline
\end{tabular}


Table 3 Benchmark regression results (ES)

\begin{tabular}{|c|c|c|c|c|c|c|}
\hline Variable & (1) & (2) & (3) & (4) & (5) & (6) \\
\hline \multirow[t]{2}{*}{ CER } & $2.607^{* * *}$ & $4.156^{* * *}$ & $4.214^{* * *}$ & $3.683^{* * *}$ & $2.893^{* * *}$ & $2.431^{* * *}$ \\
\hline & $(0.4494)$ & $(0.6508)$ & $(0.6492)$ & $(0.6141)$ & $(0.5776)$ & $(0.5594)$ \\
\hline \multirow[t]{2}{*}{$M E R$} & $3.728^{* * *}$ & $4.621^{* * *}$ & $4.816^{* * *}$ & $4.268^{* * *}$ & $3.384^{* * *}$ & $3.091^{* * *}$ \\
\hline & $(0.2563)$ & $(0.3731)$ & $(0.3832)$ & $(0.3667)$ & $(0.3548)$ & $(0.3438)$ \\
\hline \multirow[t]{2}{*}{ PER } & $0.882^{* * *}$ & $3.379^{* * *}$ & $3.278^{* * *}$ & $2.804^{* * *}$ & $2.254^{* * *}$ & $1.849^{* * *}$ \\
\hline & $(0.2028)$ & $(0.7912)$ & $(0.7899)$ & $(0.7453)$ & $(0.6956)$ & $(0.6711)$ \\
\hline \multirow[t]{2}{*}{ Inter } & & $-9.706^{* * *}$ & $-9.591^{* * *}$ & $-8.193^{* * *}$ & $-6.493^{* *}$ & $-5.789^{* *}$ \\
\hline & & $(2.9740)$ & $(2.9644)$ & $(2.7938)$ & $(2.6040)$ & (2.5039) \\
\hline \multirow[t]{2}{*}{$N R$} & & & $-10.988^{* *}$ & $-14.595^{* * *}$ & $-19.523^{* * *}$ & $-14.516^{* * *}$ \\
\hline & & & $(5.2071)$ & $(4.9180)$ & $(4.6048)$ & $(4.4892)$ \\
\hline \multirow[t]{2}{*}{$R C$} & & & & $9.045^{* * *}$ & $7.539^{* * *}$ & $16.999^{* * *}$ \\
\hline & & & & (1.1073) & (1.0430) & $(1.7563)$ \\
\hline \multirow[t]{2}{*}{$I T$} & & & & & $17.386^{* * *}$ & $15.148^{* * *}$ \\
\hline & & & & & (1.9413) & $(1.8961)$ \\
\hline \multirow[t]{2}{*}{$F L$} & & & & & & $4.635^{* * *}$ \\
\hline & & & & & & $(0.7069)$ \\
\hline \multirow[t]{2}{*}{ _cons } & $-55.959^{* * *}$ & $-31.861^{* * *}$ & $-33.791^{* * *}$ & $-26.317^{* * *}$ & $-20.9917^{* * *}$ & $-17.664^{* *}$ \\
\hline & $(3.7326)$ & $(8.2582)$ & (8.2808) & $(7.8430)$ & $(7.3152)$ & (7.0459) \\
\hline \multirow[t]{2}{*}{ Hausman } & \multicolumn{6}{|c|}{62.00} \\
\hline & \multicolumn{6}{|c|}{$(0.0000)$} \\
\hline \multirow[t]{2}{*}{$F$} & 23.63 & 24.01 & 24.33 & 21.46 & 17.95 & 18.56 \\
\hline & $(0.0000)$ & $(0.0000)$ & $(0.0000)$ & $(0.0000)$ & $(0.0000)$ & $(0.0000)$ \\
\hline$N$ & 540 & 540 & 540 & 540 & 540 & 540 \\
\hline
\end{tabular}

Note: $* * *, * * *$ indicate significance at the level of $1 \%, 5 \%$, and $10 \%$, respectively. Values in parentheses indicate standard errors. The lower bracket of the Hausman test indicate the $\mathrm{P}$ value, the bracket below $\mathrm{F}$ test is the adjoint probability of statistics.

\subsection{Robustness test}

(1) Key independent variables lag by one period

Considering that the main body of research often has a time lag in response to environmental regulations, that is, the effectiveness of environmental regulations will take a period of time to come into play. Therefore, this paper will examine the impact of the lagging first-phase variables of three types of environmental regulations on the transformation and upgrading of industrial structure to test the robustness of the benchmark model estimation results. It can be seen from Table 4 that the sign and size of the regression coefficients of the key independent variables and control variables have not changed significantly, and it can be concluded that the benchmark regression results of this paper are robust. 
Table 4 Robustness test (Key independent variables lag by one period)

\begin{tabular}{ccc}
\hline Variable & TL & ES \\
\hline CER & $-0.017^{* *}$ & $2.821^{* * *}$ \\
& $(0.0075)$ & $(0.6354)$ \\
PER & $-0.016^{* *}$ & $3.449^{* * *}$ \\
& $(0.0079)$ & $(0.3694)$ \\
Inter & $-0.038^{* *}$ & $3.264^{* * *}$ \\
& $(0.0164)$ & $(0.7582)$ \\
NR & 0.092 & $-9.041^{* * *}$ \\
& $(0.0595)$ & $(2.7499)$ \\
$R C$ & 0.051 & $-12.421^{* * *}$ \\
& $(0.1001)$ & $(4.6310)$ \\
IT & $-0.112^{* * *}$ & $17.005^{* * *}$ \\
& $(0.0397)$ & $(1.8382)$ \\
FL & $-0.162^{* * *}$ & $13.659^{* * *}$ \\
& $(0.4776)$ & $(2.2086)$ \\
cons & $-0.106^{* * *}$ & $4.572^{* * *}$ \\
& $(0.0165)$ & $(0.7624)$ \\
Hausman & $0.275^{*}$ & -12.209 \\
& $(0.1653)$ & $(7.6417)$ \\
\hline \multirow{2}{*}{ F } & 20.25 & 65.39 \\
& $(0.0164)$ & $(0.0000)$ \\
\hline
\end{tabular}

Note: $* * *, * *, *$ indicate significance at the level of $1 \%, 5 \%$, and $10 \%$, respectively. Values in parentheses indicate standard errors. The lower bracket of the Hausman test indicate the $\mathrm{P}$ value, the bracket below $\mathrm{F}$ test is the adjoint probability of statistics.

(2) Replace the key independent variables

Since there are many indicators for environmental regulation, this paper will select an alternative indicator for the three types of environmental regulations to test the robustness of the model. Among them, the CER chooses "the number of environmental administrative punishment cases" as a substitute indicator. MER select the "three-simultaneous deposit" as an alternative indicator, but based on the availability of data, use the "implementation of the three-simultaneous project environmental investment amount" for specific measurement in each region. VER select "the total number of environmental letters and visits in the region" as a substitute indicator. It can be seen from Table 5 that after replacing the independent variables, the signs and sizes of the regression coefficients of the key independent variables and the control variables also did not change significantly. It can be concluded that the benchmark regression results of this paper are robust. 


\begin{tabular}{|c|c|c|}
\hline Variable & $\mathrm{TL}$ & ES \\
\hline \multirow[t]{2}{*}{$C E R$} & $-0.009^{* *}$ & $2.122^{* * *}$ \\
\hline & $(0.0043)$ & $(0.1806)$ \\
\hline \multirow[t]{2}{*}{$M E R$} & $-0.005^{* *}$ & $3.010^{* * *}$ \\
\hline & $(0.0023)$ & $(0.3412)$ \\
\hline \multirow[t]{2}{*}{ PER } & $-0.033^{* *}$ & $3.104^{* * *}$ \\
\hline & $(0.0151)$ & $(0.1134)$ \\
\hline \multirow[t]{2}{*}{ Inter } & 0.012 & $-7.153^{* * *}$ \\
\hline & $(0.0035)$ & (1.4507) \\
\hline \multirow[t]{2}{*}{$N R$} & 0.089 & $-7.965^{* *}$ \\
\hline & $(0.0516)$ & (3.9231) \\
\hline \multirow[t]{2}{*}{$R C$} & $-0.053^{* * *}$ & $9.002^{* * *}$ \\
\hline & $(0.0139)$ & (1.6883) \\
\hline \multirow[t]{2}{*}{$I T$} & $-0.070^{* *}$ & $9.765^{* * *}$ \\
\hline & $(0.0304)$ & (1.7767) \\
\hline \multirow[t]{2}{*}{$F L$} & $-0.084^{* * *}$ & $1.476^{* *}$ \\
\hline & $(0.0163)$ & $(0.6729)$ \\
\hline \multirow[t]{2}{*}{ _cons } & $0.444^{* * *}$ & 5.605 \\
\hline & $(0.0439)$ & (1.8147) \\
\hline \multirow[t]{2}{*}{ Hausman } & 26.57 & 15.26 \\
\hline & $(0.0164)$ & $(0.0841)$ \\
\hline \multirow[t]{2}{*}{$F$} & 56.50 & 23.42 \\
\hline & $(0.0000)$ & $(0.0000)$ \\
\hline$N$ & 540 & 540 \\
\hline
\end{tabular}
indicate standard errors. The lower bracket of the Hausman test indicate the $\mathrm{P}$ value, the bracket below $\mathrm{F}$ test is the adjoint probability of statistics.

(3) Change the model estimation method

Considering that fixed effects regression may have endogenous problems, the generalized distance estimation method is used to estimate the robustness of the benchmark model. System Generalized Distance Estimation (System GMM) combines differential GMM and horizontal GMM into one, and performs GMM estimation as a simultaneous equation system. In the system GMM, the endogenous explanatory variable lag is used as its own instrumental variable, which not only improves the efficiency and robustness of the estimation, but also estimates the regression coefficient that does not change with time. Based on this, this paper adopts a two-step system GMM estimation method to test the robustness of the above-mentioned benchmark model. It can be seen from Table 6 that the model has passed the $\mathrm{AR}(1), \mathrm{AR}(2)$ and Sargan tests. The model does not have the problem of second-order autocorrelation, and there is no problem of over-identification of instrumental variables. Therefore, the regression result is reliable. It is known from the regression coefficient and significance that the sign and significance of the coefficient have not changed significantly, again verifying the robustness of the benchmark regression results in this paper. 
Table 6 Robustness test (change model estimation method)

\begin{tabular}{|c|c|c|}
\hline Variable & $\mathrm{TL}$ & ES \\
\hline \multirow[t]{2}{*}{ CER } & $-0.049^{* *}$ & $1.578^{* * *}$ \\
\hline & $(0.0129)$ & $(0.3434)$ \\
\hline \multirow[t]{2}{*}{$M E R$} & $-0.012^{* *}$ & $3.426^{* * *}$ \\
\hline & $(0.0051)$ & $(0.2722)$ \\
\hline \multirow[t]{2}{*}{ PER } & $-0.028^{*}$ & $1.864^{* * *}$ \\
\hline & $(0.0170)$ & $(0.5257)$ \\
\hline \multirow[t]{2}{*}{ Inter } & 0.061 & -2.966 \\
\hline & $(0.0548)$ & (1.9279) \\
\hline \multirow[t]{2}{*}{$N R$} & 0.269 & $-17.497^{* *}$ \\
\hline & $(0.2147)$ & $(3.5939)$ \\
\hline \multirow[t]{2}{*}{$R C$} & $-0.054^{* * *}$ & $10.459^{* * *}$ \\
\hline & $(0.0128)$ & (3.4417) \\
\hline \multirow[t]{2}{*}{$I T$} & $-0.178^{* * *}$ & $9.210^{* * *}$ \\
\hline & $(0.0589)$ & (3.0179) \\
\hline \multirow[t]{2}{*}{$F L$} & $-0.088^{* *}$ & $1.282^{* *}$ \\
\hline & $(0.0404)$ & $(0.6051)$ \\
\hline \multirow[t]{2}{*}{ _cons } & $0.581^{* * *}$ & -18.894 \\
\hline & $(0.2058)$ & $(5.5321)$ \\
\hline Province & Yes & Yes \\
\hline Year & Yes & Yes \\
\hline \multirow[t]{2}{*}{$A R(1)$} & -3.45 & -2.66 \\
\hline & $(0.0006)$ & $(0.0077)$ \\
\hline \multirow[t]{2}{*}{$A R(2)$} & 0.19 & 1.10 \\
\hline & $(0.8652)$ & $(0.2694)$ \\
\hline Sargan & 0.26 & 0.17 \\
\hline$N$ & 540 & 540 \\
\hline
\end{tabular}

Note: $* * *, * *, *$ indicate significance at the level of $1 \%, 5 \%$, and $10 \%$, respectively. Values in parentheses indicate standard errors. The AR(1) and AR(2) tests in parentheses below are the adjoint probabilities of the statistics.

\subsection{Non-linearity test}

This paper selects the level of regional economic development as the threshold variable, and uses the Bootstrap method to repeatedly sample 300 times for threshold self-sampling inspection. Table 7 and 9 show the results of the 300 self-sampling tests, and Table 8 and 10 show the estimated thresholds and $95 \%$ confidence intervals. According to the test results, under the condition of the advanced industrial structure as the dependent variable, the single threshold and double threshold effects of the three types of environmental regulations have passed the $1 \%$ significance test, but the triple threshold effect is not significant. Under the condition of rationalization of the industrial structure as the dependent variable, the single threshold and double threshold effects of the CER and the VER have passed the significance test of $10 \%$ and above, while the single threshold effect of market incentive environmental regulation only passes the significance test of $5 \%$. 
Table 7 Self-sampling inspection of threshold effect (ES)

\begin{tabular}{cccccccc}
\hline \multirow{2}{*}{ Threshold variable } & Threshold nature & F & P & BS & \multicolumn{3}{c}{ Critical value } \\
& & & & & $1 \%$ & $5 \%$ & $10 \%$ \\
\hline \multirow{3}{*}{ CER } & Single & $348.56^{* * *}$ & 0.0000 & 300 & 112.411 & 84.713 & 68.402 \\
& Double & $204.31^{* * *}$ & 0.0000 & 300 & 63.496 & 41.810 & 34.068 \\
& Triple & 94.65 & 0.6867 & 300 & 282.092 & 216.954 & 197.281 \\
\multirow{2}{*}{ MER } & Single & $310.56^{* * *}$ & 0.0000 & 300 & 117.289 & 87.046 & 76.631 \\
& Double & $234.84^{* * *}$ & 0.0000 & 300 & 72.049 & 45.515 & 36.313 \\
& Triple & 89.15 & 0.6600 & 300 & 269.008 & 214.654 & 187.674 \\
& Single & $332.60^{* * *}$ & 0.0000 & 300 & 126.019 & 92.497 & 77.277 \\
& Double & $188.08^{* * *}$ & 0.0000 & 300 & 57.019 & 41.215 & 33.458 \\
& Triple & 76.43 & 0.6800 & 300 & 224.945 & 169.373 & 151.792 \\
\hline
\end{tabular}

501

502

Table 8 Threshold estimation results (ES)

\begin{tabular}{|c|c|c|c|c|}
\hline \multicolumn{2}{|c|}{ Threshold variable } & \multirow{2}{*}{$\frac{\text { Threshold estimate }}{2.172}$} & \multicolumn{2}{|c|}{$95 \%$ confidence interval } \\
\hline \multirow{2}{*}{ CER } & Threshold 1 & & {$[2.164$} & $2.206]$ \\
\hline & Threshold 2 & 4.661 & {$[4.487$} & $4.685]$ \\
\hline \multirow{2}{*}{$M E R$} & Threshold 1 & 2.397 & {$[2.374$} & $2.431]$ \\
\hline & Threshold 2 & 4.661 & {$[4.492$} & $4.702]$ \\
\hline \multirow{2}{*}{ PER } & Threshold 1 & 2.397 & {$[2.374$} & 2.469] \\
\hline & Threshold 2 & 4.661 & {$[4.487$} & $4.686]$ \\
\hline
\end{tabular}

Table 9 Self-sampling inspection of threshold effect (TL)

\begin{tabular}{cccccccc}
\hline \multirow{2}{*}{ Threshold variable } & Threshold nature & $\mathrm{F}$ & $\mathrm{P}$ & $\mathrm{BS}$ & \multicolumn{3}{c}{ Critical value } \\
& & & & & $1 \%$ & $5 \%$ & $10 \%$ \\
\hline \multirow{3}{*}{ CER } & Single & $55.51^{* *}$ & 0.0267 & 300 & 59.474 & 47.365 & 40.761 \\
& Double & $34.71^{*}$ & 0.0733 & 300 & 56.825 & 39.819 & 30.287 \\
& Triple & 13.65 & 0.4933 & 300 & 46.992 & 35.493 & 28.386 \\
\multirow{2}{*}{ MER } & Single & $56.06^{* *}$ & 0.0167 & 300 & 70.817 & 46.830 & 38.257 \\
& Double & 30.25 & 0.1233 & 300 & 69.601 & 40.105 & 32.001 \\
& Single & $50.30^{* *}$ & 0.0467 & 300 & 72.371 & 49.954 & 39.268 \\
& Double & $37.55^{*}$ & 0.0733 & 300 & 61.697 & 46.963 & 31.845 \\
& Triple & 11.96 & 0.6267 & 300 & 63.906 & 41.200 & 32.086 \\
\hline
\end{tabular}

Note: $* * *, * *, *$ indicate significance at the level of $1 \%, 5 \%$, and $10 \%$.

Table 10 Threshold estimation results (TL)

\begin{tabular}{|c|c|c|c|c|}
\hline \multicolumn{2}{|c|}{ Threshold variable } & \multirow{2}{*}{$\frac{\text { Threshold estimate }}{0.347}$} & \multicolumn{2}{|c|}{$95 \%$ confidence interval } \\
\hline \multirow{2}{*}{ CER } & Threshold 1 & & {$[0.274$} & $0.371]$ \\
\hline & Threshold 2 & 1.462 & {$[1.432$} & $1.464]$ \\
\hline$M E R$ & Threshold 1 & 0.347 & {$[0.274$} & $0.371]$ \\
\hline \multirow{2}{*}{ PER } & Threshold 1 & 0.347 & {$[0.274$} & $0.371]$ \\
\hline & Threshold 2 & 1.462 & {$[1.432$} & $1.464]$ \\
\hline
\end{tabular}


Based on the above threshold effect test analysis, it can be seen that the three types of environmental regulations have a threshold effect on the transformation and upgrading of the industrial structure with the regional economic development level as the threshold variable. Therefore, the threshold model is regressed. Table 11 and Table 12 are the regression results of the threshold model for the advanced and rationalized industrial structure of the dependent variable. It can be seen from Table 11 that the three types of environmental regulations have gradually highlighted the role of environmental regulations in promoting the advancement of the industrial structure with the improvement of the level of regional economic development. In particular, when the level of regional economic development is lower than 2.397, the VER does not play a significant positive role in the advancement of the industrial structure. This shows that the level of regional economic development, as the material basis for the transformation and upgrading of the industrial structure, is crucial to the realization of environmental regulation policies to promote industrial transformation and upgrading. If the regional economic development level is high, when the environmental regulation policy is implemented, it can use its own economic advantages to achieve industrial transformation and upgrading smoothly. However, if the regional economic development level is low, the local government may cause the effect of environmental regulation policies to be greatly reduced in order to develop the economy.

It can be seen from Table 12 that MER only has a single threshold value of 0.347 when the regional economic development level is used as the threshold variable. Similarly, the three types of environmental regulations have gradually highlighted the role of environmental regulations in promoting the rationalization of industrial structure with the improvement of the level of regional economic development. And when the level of economic development is low, CER and VER have not effectively promoted the improvement of the level of industrial structure rationalization.

Table 11 Regression results of panel threshold model

\begin{tabular}{|c|c|c|c|}
\hline Variable & & ES & \\
\hline$C E R^{*} I(E D<2.172)$ & $\begin{array}{l}0.678^{* * *} \\
(0.2626)\end{array}$ & & \\
\hline$C E R^{*} I(2.172<E D<4.661)$ & $\begin{array}{l}1.254^{* * *} \\
(0.2647)\end{array}$ & & \\
\hline$C E R * I(E D>4.661)$ & $\begin{array}{l}1.928^{* * *} \\
(0.2580)\end{array}$ & & \\
\hline$M E R * I(E D<2.397)$ & & $\begin{array}{l}1.493^{* * *} \\
(0.1670)\end{array}$ & \\
\hline$M E R^{*} I(2.397<E D<4.661)$ & & $\begin{array}{l}1.889^{* * *} \\
(0.1693)\end{array}$ & \\
\hline$M E R * I(E D>4.661)$ & & $\begin{array}{l}2.320^{* * *} \\
(0.1689)\end{array}$ & \\
\hline$M E R * I(E D<2.397)$ & & & $\begin{array}{c}0.143 \\
(0.3044)\end{array}$ \\
\hline$M E R^{*} I(2.397<E D<4.661)$ & & & $\begin{array}{l}0.809^{* * *} \\
(0.2697)\end{array}$ \\
\hline$M E R * I(E D>4.661)$ & & & $\begin{array}{l}1.607^{* * *} \\
(0.2738)\end{array}$ \\
\hline Control variable & Yes & Yes & Yes \\
\hline _cons & $\begin{array}{c}-4.492 \\
(2.8186)\end{array}$ & $\begin{array}{l}-9.210^{* * *} \\
(2.4506)\end{array}$ & $\begin{array}{c}-35.032^{* * *} \\
(4.2959)\end{array}$ \\
\hline$N$ & 540 & 540 & 540 \\
\hline
\end{tabular}


Table 12 Regression results of panel threshold model

\begin{tabular}{|c|c|c|c|}
\hline Variable & & $\mathrm{TL}$ & \\
\hline$C E R^{*} I(E D<0.347)$ & $\begin{array}{c}-0.010 \\
(0.0077)\end{array}$ & & \\
\hline$C E R^{*} I(0.347<E D<1.462)$ & $\begin{array}{l}-0.026^{* *} \\
(0.0124)\end{array}$ & & \\
\hline$C E R * I(E D>1.462)$ & $\begin{array}{c}-0.066^{* * *} \\
(0.0189)\end{array}$ & & \\
\hline$M E R * I(E D<0.347)$ & & $\begin{array}{l}-0.009^{*} \\
(0.0059)\end{array}$ & \\
\hline$M E R * I(E D>0.347)$ & & $\begin{array}{l}-0.064^{* *} \\
(0.0265)\end{array}$ & \\
\hline$P E R^{*} I(E D<0.347)$ & & & $\begin{array}{c}0.004 \\
(0.0078)\end{array}$ \\
\hline$P E R^{*} I(0.347<E D<1.462)$ & & & $\begin{array}{l}-0.025^{* *} \\
(0.0124)\end{array}$ \\
\hline$P E R^{*} I(E D>1.462)$ & & & $\begin{array}{l}-0.076^{* * *} \\
(0.0157)\end{array}$ \\
\hline Control variable & Yes & Yes & Yes \\
\hline _cons & $\begin{array}{l}0.593^{* * *} \\
(0.0854)\end{array}$ & $\begin{array}{l}0.520^{* * *} \\
(0.0816)\end{array}$ & $\begin{array}{l}0.624^{* * *} \\
(0.1277)\end{array}$ \\
\hline$N$ & 540 & 540 & 540 \\
\hline
\end{tabular}

Note: $* * *, * *, *$ indicate significance at the level of $1 \%, 5 \%$, and $10 \%$, respectively. Values in parentheses indicate standard errors.

\subsection{Mechanism test}

Since environmental resources are non-exclusive and competitive, the negative externalities caused by environmental pollution need to be resolved through government forces. The theory of government intervention believes that the externality of environmental pollution cannot be solved by the market mechanism itself, while the government has complete information and can rely on environmental regulations to internalize external effects. Porter et al (1995) expanded and deepened this theory and proposed that strict environmental regulations will induce technological innovation in enterprises, thereby achieving the goal of a win-win situation for environmental protection and economic development, namely the "Porter Hypothesis". Specifically, on the one hand, enterprises affected by environmental regulations may choose to improve production processes and pollution control technologies in order to avoid being punished by environmental regulations. On the other hand, the green subsidy policy may receive investment in technological innovation, thereby increasing the level of green technological innovation, and ultimately promoting the transformation and upgrading of the industrial structure. Those who hold the opposite view to Porter's hypothesis believe that because the cost of complying with environmental regulations always exists, it will have a crowding-out effect on innovation funds, thereby hindering the transformation and upgrading of industrial structure to a certain extent, that is, "following the cost theory." Therefore, this paper further examines whether environmental regulation can achieve the transformation and upgrading of industrial structure through the intermediary effect of technological innovation.

Before foreign capital enters the host country, the strength of environmental regulations in a country or region will inevitably affect the location of foreign investment. The "Pollution Paradise Hypothesis" points out that in order to maximize profits, pollution-intensive companies will transfer their industries to countries with lower levels of environmental regulation. On the one hand, strict environmental regulations have become an obstacle to the capital entry of some polluting companies, increasing the cost 
of foreign companies purchasing raw materials from the local area, and then squeezing out the investment in production and operation links, which is not conducive to the spillover effect of foreign capital, so it may have a negative impact on the transformation and upgrading of local industrial structure. On the other hand, the establishment of environmental regulations as a screening threshold for foreign investment can reduce the entry of pollution-intensive companies and leave room for other companies with relatively clean production. Adom and Amuakwa-Mensah (2016) believe that the technology spillover of foreign enterprises in the host country can improve the production efficiency of domestic enterprises, thus promoting the transformation and upgrading of industrial structure to a certain extent. Similarly, this paper examines whether environmental regulations can achieve industrial structural transformation and upgrading through the intermediary role of foreign direct investment.

On the basis of existing literature, it is considered that environmental regulation may have an impact on the transformation and upgrading of industrial structure through two paths: technological innovation and foreign direct investment. Therefore, in order to test whether these two paths exist or not, this paper uses the method of Baron and Kenny (1986) to build a mediation effect model with technological innovation and foreign direct investment as mediation variables to test the mechanism of environmental regulation on the transformation and upgrading of industrial structure. The mediation effect model is set as follows.

$$
E S_{i t}=\theta_{0}+\theta_{1} E R_{j i t}+\theta_{2} X_{i t}+\xi_{i t}
$$

$$
P A_{i t}=\gamma_{0}+\gamma_{1} E R_{j i t}+\xi_{i t}
$$

$$
E S_{i t}=\delta_{0}+\delta_{1} E R_{j i t}+\delta_{2} P A_{i t}+\delta_{3} X_{i t}+\xi_{i t}
$$

$$
F D I_{i t}=\eta_{0}+\eta_{1} E R_{j i t}+\xi_{i t}
$$

$$
E S_{i t}=\rho_{0}+\rho_{1} E R_{j i t}+\rho_{2} F D I_{i t}+\rho_{3} X_{i t}+\xi_{i t}
$$

$$
T L_{i t}=\theta_{0}+\theta_{1} E R_{j i t}+\theta_{2} X_{i t}+\xi_{i t}
$$

$$
P A_{i t}=\gamma_{0}+\gamma_{1} E R_{j i t}+\xi_{i t}
$$

$$
T L_{i t}=\delta_{0}+\delta_{1} E R_{j i t}+\delta_{2} P A_{i t}+\delta_{3} X_{i t}+\xi_{i t}
$$

$$
F D I_{i t}=\eta_{0}+\eta_{1} E R_{j i t}+\xi_{i t}
$$

\[ L_{i t}=\rho_{0}+\rho_{1} E R_{j i t}+\rho_{2} F D I_{i t}+\rho_{3} X_{i t}+\xi_{i t} \]
Where, ER stands for environmental regulations, $\mathrm{j}=1,2,3$, which respectively represent CER, MER, and VER. PA is technological innovation. The current indicators for measuring technological innovation include R\&D investment, the number of scientific researchers, and the number of patents. We uses the number of patent applications to measure. FDI is foreign direct investment, which is measured by the ratio of the amount of regional foreign direct investment to local GDP. The meaning of other variables is consistent with the benchmark model.

Table 13 reports the estimated results of technological innovation as an intermediary variable. It can be seen that the three types of environmental regulations all have a significant positive role in promoting technological innovation, which can be the next step of the mediation effect test. After the intermediary variable PA is introduced into the model, the regression coefficients of CER are still significant, while the regression coefficients of MER and VER have become insignificant. Part of the mediating effect exists in the process of industrial structure transformation and upgrading, and there is a complete mediating effect in the process of MER and VER on the process of industrial structure transformation and upgrading. This also shows that China's MER and VER have the "Porter Hypothesis" in their 
604 605

influence on the transformation and upgrading of industrial structure, while the CER is not.

Table 13 Estimation results of mechanism test (PA)

\begin{tabular}{cccccc}
\hline Variable & PA & ES & ES & TL & TL \\
\hline CER & $1.100^{* * *}$ & $1.489^{* * *}$ & $0.869^{* *}$ & $-0.017^{* *}$ & -0.008 \\
& $(0.1695)$ & $(0.3849)$ & $(0.3671)$ & $(0.0083)$ & $(0.0083)$ \\
MER & $1.416^{* * *}$ & $2.538^{* * *}$ & 1.687 & $-0.009^{*}$ & 0.003 \\
& $(0.0967)$ & $(0.2485)$ & $(1.2529)$ & $(0.0053)$ & $(0.0057)$ \\
PER & $0.388^{* * *}$ & $0.351^{* *}$ & 0.142 & $-0.010^{* * *}$ & $-0.007^{*}$ \\
& $(0.0765)$ & $(0.1756)$ & $(0.1659)$ & $(0.0038)$ & $(0.0037)$ \\
PA & & $0.882^{* * *}$ & & $-0.0127^{* * *}$ \\
Control & No & & $(0.1030)$ & & $(0.0023)$ \\
variable & & Yes & Yes & Yes & Yes \\
cons & $-17.776^{* * *}$ & $-31.646^{* * *}$ & $-22.880^{* * *}$ & $0.617^{* * *}$ & $0.491^{* * *}$ \\
& $(1.4081)$ & $(3.6299)$ & $(3.5451)$ & $(0.0787)$ & $(0.0798)$ \\
$N$ & 540 & 540 & 540 & 540 & 540 \\
\hline
\end{tabular}

Note: $* * *, * * *$ indicate significance at the level of $1 \%, 5 \%$, and $10 \%$, respectively. Values in parentheses indicate standard errors.

Table 14 reports the estimated results of foreign direct investment as an intermediary variable. The results show that CER and MER have a certain hindering effect on foreign direct investment, while VER has no obvious impact on foreign direct investment, indicating that with the improvement of China's environmental regulations, restrictions some foreign investment activities with high pollution levels. After adding the intermediary variable FDI to the model, the regression coefficients of the three types of environmental regulations are still significant, and the coefficient of the intermediary variable FDI is not significant, indicating that foreign direct investment has only a partial mediating effect in the process of the three types of environmental regulations affecting the industrial structure transformation and upgrading.

Table 14 Estimation results of mechanism test (FDI)

\begin{tabular}{|c|c|c|c|c|c|}
\hline Variable & FDI & ES & ES & TL & TL \\
\hline \multirow[t]{2}{*}{ CER } & $-0.109^{*}$ & $1.489^{* * *}$ & $1.427^{* * *}$ & $-0.017^{* *}$ & $-0.017^{* *}$ \\
\hline & $(0.0612)$ & $(0.3849)$ & $(0.3813)$ & $(0.0083)$ & $(0.0083)$ \\
\hline \multirow[t]{2}{*}{$M E R$} & $-0.064^{*}$ & $2.538^{* * *}$ & $2.562^{* * *}$ & $-0.009^{*}$ & $-0.009 *$ \\
\hline & $(0.0349)$ & $(0.2485)$ & $(0.2460)$ & $(0.0053)$ & $(0.0053)$ \\
\hline \multirow[t]{2}{*}{ PER } & 0.014 & $0.351^{* *}$ & $0.386^{* *}$ & $-0.010^{* * *}$ & $-0.010^{* * *}$ \\
\hline & $(0.0276)$ & $(0.1756)$ & $(0.1741)$ & $(0.0038)$ & $(0.0038)$ \\
\hline \multirow[t]{2}{*}{$F D I$} & & & $-1.120^{* * *}$ & & 0.008 \\
\hline & & & $(0.3286)$ & & $(0.0072)$ \\
\hline Control & No & Yes & Yes & Yes & Yes \\
\hline \multicolumn{6}{|l|}{ variable } \\
\hline \multirow[t]{2}{*}{ _cons } & $1.943^{* * *}$ & $-31.646^{* * *}$ & & $0.617^{* * *}$ & $0.620^{* * *}$ \\
\hline & $(0.5084)$ & (3.6299) & & $(0.0787)$ & $(0.0787)$ \\
\hline$N$ & 540 & 540 & 540 & 540 & 540 \\
\hline
\end{tabular}




\section{Research conclusions and policy implications}

Since the reform and opening up, China's economic development speed and overall scale have made remarkable achievements, but at the same time, it is also facing problems such as overcapacity and overall de-realization to virtuality, and the problem of irrational and unbalanced industrial structure has gradually become prominent (Heinrich and Dai, 2016). To transform the mode of economic development and lead the economy to high-quality development. The Chinese government has chosen a path that can both improve the environment and promote sustainable economic development. For this reason, it has issued a number of environmental policies to deal with environmental problems in the process of industrial development. However, there are obvious differences between different types of environmental regulations, which are reflected in different environmental protection tendencies and purposes, and there are also significant differences in policy implementation. Therefore, quantitative assessment of heterogeneous environmental regulations has become an empirical problem that needs to be solved urgently for the transformation and upgrading of China's industrial structure. Therefore, this paper describes the transformation and upgrading of industrial structure from two levels of industrial structure rationalization and advancement. On this basis, it uses panel data models and threshold models to empirically test the different effects of heterogeneous environmental regulations on industrial structure transformation and upgrading, and further analyzes which influence mechanism. The main conclusions are as follows: (1) The level of rationalization of China's industrial structure increased year by year from 2000 to 2017, but there is still a certain distance from the optimization level. The industrial structure is changing from a low-level form of "primary, secondary, and tertiary industries", transformed into a highlevel structure of "tertiary industry, secondary industry, and primary industry". (2) The three types of environmental regulation measures can effectively reduce the deviation degree of industrial structure and improve the advanced level of industrial structure, and the effect of MER on the advanced level of industrial structure is significantly higher than that of CER and PER. However, from the regression results of the three interaction terms, it has no effect on the transformation of industrial structure upgrading has a positive promoting effect. (3) According to the results of non-linear testing, the three types of environmental regulations have gradually highlighted the role of environmental regulations in promoting the transformation and upgrading of the industrial structure as the level of regional economic development increases. (4) In the examination of the mechanism of action, it is found that technological innovation has a partial mediating effect in the process of the impact of CER on the transformation and upgrading of industrial structure. MER and VER have a complete intermediary effect in the process of industrial structure transformation and upgrading, while foreign direct investment has only a partial intermediary effect in the process of the three types of environmental regulations affecting industrial structure transformation and upgrading.

Based on the above research conclusions and combined with theoretical analysis, the following policy implications are drawn. First, improve the environmental law enforcement system, continuously innovate law enforcement methods, fundamentally solve the problems of extensive, random law enforcement and unfair law enforcement, and effectively improve the reasonable level of command-andcontrol environmental regulations. The second is to build a market incentive-based environmental regulation and guidance mechanism. MER has become the main regulatory force to promote industrial transformation and upgrading. China should continue to carry out in-depth emissions trading and carbon emissions trading pilot work, summarize and improve its regulatory methods, and finally promote it to all provinces across the country to obtain environmental dividends. The third is to establish and improve laws and regulations on public participation, improve the government information disclosure system, strengthen corporate information disclosure systems, give full play to the role of media supervision and reputation mechanisms, increase education and publicity, encourage people to participate in environmental protection, and actively play VER promotes the transformation and upgrading of industrial structure. Fourth, attach importance to the mediating effect of various types of environmental regulations. First, increase investment in technological innovation in the manufacturing industry, accelerate the transformation, utilization, promotion and application of research and development results, and improve the intellectual property protection and other invention and creation incentive systems. 
Secondly, make environmental regulations as the threshold for the introduction of foreign investment, by screening some pollution-intensive and resource-intensive enterprises, ensuring the quality of foreign investment, and actively digesting the green technology and management experience of foreign-funded enterprises. Finally, the interaction and coordination mechanism among CER, MER and VER should be brought into play. By coordinating the three types of environmental regulations, to make up for the shortcomings of a single environmental regulation, and finally form a joint force of environmental regulations to achieve the goal of industrial transformation and upgrading.

Funding This study was financed by the National Natural Science Foundation of China, under grant number 71473295. The Foundation of Southwest University, under grant number SWU1909516.

Author contributions Lianghu Wang and Zhao Wang conceived and designed the research question. Lianghu Wang constructed the models and analyzed the optimal solutions. Lianghu Wang wrote the paper. Yatian Ma reviewed and edited the manuscript. All authors read and approved the manuscript.

Data availability The datasets generated and/or analyzed during the current study are property of National Bureau of Statistics, they are available from the corresponding author who will inform National Bureau of Statistics that the data will be released on reasonable request.

\section{Compliance with ethical standards}

Conflict of interests The authors declare that they have no conflict of interest.

Ethics approval and consent to participate Not applicable

Consent to participate Not applicable

Consent to publish Not applicable

\section{References}

Abu Seman NA, Govindan K, Mardani A, Zakuan N, Saman MZ, Hooker RE, Ozkul S (2019) The mediating effect of green innovation on the relationship between green supply chain management and environmental performance. J Clean Prod 229: 115-127

Adom PK, Amuakwa MF (2016) What drives the energy saving role of FDI and industrialization in East Africa? Renew Sustain Energy Rev 65: 925-942

Ahmed A, Uddin GS, Sohag, K (2016) Biomass energy, technological progress and the environmental Kuznets curve: evidence from selected European countries. Biomass Bioenergy 90: 202-208

Alpay E, Buccola S, Kerkvie J (2002) Productivity growth and environmental regulation in Mexican and U.S. food manufacturing, J America Agricultural Econ 84: 887-901

Baron RM, Kenny DA (1986) The moderator-mediator variable distinction in social psychological research: conceptual, strategic, and statistical considerations. J Personal So Psycho 51: 1173-1182

Burton DM, Gomez IA, Love HA (2011) Environmental regulation cost and industry structure changes. Land Economics 87: 545-557

Chen X, Qian WW (2020) Effect of marine environmental regulation on the industrial structure adjustment of manufacturing industry: An empirical analysis of China's eleven coastal provinces. Marine Policy 113: 103797

Cole MA, Elliott RJ, Shimamoto K (2005) Industrial characteristics, environmental regulations and air pollution: an analysis of the UK manufacturing sector. J Environ Econ Manag 50: 121-143

Dai J, Chen B, Hayat T, Alsaedi A, Ahmad B (2015) Sustainability-based economic and ecological 
evaluation of a rural biogas-linked agro-ecosystem. Renew. Sustain Energy Rev 41: 347-355

El-Zayat H, Ibraheem G, Kandil S (2006) The response of industry to environmental regulations in Alexandria, Egypt. J Environ Manag 79: 207-214

Ernst D, (1998) Catching-up, crisis and industrial upgrading, evolutionary aspects of technological learning in Korea's electronics industry. J Asia Pacific Manag 15: 247-283

Gouldson A, Carpenter A, Afionis S (2014) An international comparison of the outcomes of environmental regulation. Environ Res Lett 9: 074019

Guo Y, Tong L, Mei L (2020) The effect of industrial agglomeration on green development efficiency in Northeast China since the revitalization. J Clean Prod 258: 120584

Gurtoo A, Antony SJ (2007) Environmental regulations: indirect and unintended consequences on economy and business. Manag Environ Qual 18: 626-642

Hansen BE (1999) Threshold effects in non-dynamic panels: Estimation, testing, and inference. J Econ 93: $345-368$

Heinrich T, Dai S (2016) Diversity of firm sizes, complexity, and industry structure in the Chinese economy. St Cha Econ Dyna 37: 90-106

Hou J, Teo TS, Zhou F, Lim MK, Chen H (2018) Does industrial green transformation successfully facilitate a decrease in carbon intensity in China? An environmental regulation perspective, J Clean Prod 184: 1060-1071

Hu Y, Ren S, Wang Y, Chen X (2020) Can carbon emission trading scheme achieve energy conservation and emission reduction? Evidence from the industrial sector in China. Energy Econ 85:104590

Jaffe AB, Palmer K, (1997) Environmental regulation and innovation: a panel data study. Rev Econ Stat 79: 610-619

Keller W, Levinson A (2002) Environmental compliance costs and foreign direct investment inflows to U. S. States. Rev. Econ. Statist. 84: 691-703

Kheder SB, Zugravu N (2012) Environmental regulation and French firms location aboard: An economic geography model in an international comparativestudy. Eco Econ 77: 48-61

Levine R (1997) Financial development and economic growth: Views and agenda. J Econ Liter 35: 688726

Levinson A (1996) Environmental regulations and manufacturers' location choices: Evidence from the Census of Manufactures. J Pub Econ 65: 5-29

Li XP, Yu DS, Yu JJ (2020) Spatial spillover effect of heterogeneous environmental regulation on carbon productivity: Based on the spatial dubin model. China So Sci 4: 82-96

Liao H, Deng Q (2018) A carbon-constrained eoq model with uncertain demand for remanufactured products. J Clean Prod 199: 334-347

Liu W, Tong J, Yue X (2016) How does environmental regulation affect industrial transformation? A study based on the methodology of policy simulation. Math Pro Engineer 4: 1-10

Liu W, Zhang H, Huang ZH (2008) An investigation on the relationship between the height of China's industrial structure and the process of industrialization and regional differences. Econ Pers 11: 4-8

Lu ZN, Chen H, Hao Y, Wang J, Song X, Mok TM (2017) The dynamic relationship between environmental pollution, economic development and public health: evidence from China. J Clean Prod 166: $134-147$

Millime DL, Jayjit R (2016) "Empirical tests of the pollution haven hypothesis when environmental regulation is endogenous". J App Econ 31: 652-677

Millime DL, Santanu R, Sengupta A (2009) Environmental regulations and economic activity: Influence 
on market structure. Ann Revie Res Econ 1: 99-118

Pipkin S, Fuentes A, (2017) Spurred to upgrade: a review of triggers and consequences of industrial upgrading in the global value chain literature. World Dev. 98: 536-554.

Porter ME (1991) America's green strategy. Sci. Amer. 264: 168-264

Porter ME, Linde C (1995) Toward a new conception of the environment competitiveness relationship. J Econ Pers 9: 97-118

Ramanathan R, Black A, Nath P, Muyldermans L (2010) Impact of environmental regulations on innovation and performance in the UK industrial sector. Manag Decis 48: 1493-1513

Shehabi M (2020) Diversification effects of energy subsidy reform in oil exporters: illustrations from Kuwait. Energy Policy 138: 110966

Shen N, Liao HL, Deng RM (2019) Different types of environmental regulations and the heterogeneous influence on the environmental total factor productivity: Empirical analysis of China's industry. J Clean Prod 11: 71-184

Solarin SA, Al-Mulali U, Musah I, et al (2017) Investigating the pollution haven hypothesis in Ghana: An empirical investigation, Energy. 124, 706-719

Taylor CM, Pollard SJ, Angus AJ, Rocks SA (2013) Better by design: Rethinking interventions for better environmental regulation. Sci Total Environ 447: 488-499

Tong J, Liu W, Xue J (2016) Environmental regulation, factor input structure and industrial transformation and upgrading. Econ Res 7: 43-57

Wang X, Zhang C, Zhang, Z (2019) Pollution haven or porter? The impact of environmental regulation on location choices of pollution-intensive firms in China. J Environ Manag 248: 109248

Wu L, Jia XY, Wu C (2020) The impact of heterogeneous environmental regulation on China's green total factor productivity. China Pop Re. Environ 10: 82-92

Xie RH, Yuan YJ (2014) Research on the effect of environmental regulation to industrial restructuringempirical test based on provincial panel data of China, China Ind Econ 8: 57-69

Xie RH, Yuan YJ, Huang J (2017) Different types of environmental regulations and heterogeneous influence on "Green" Productivity: Evidence from China Eco Econ 132:104-112

Yu X, Wang P (2020) Economic effects analysis of environmental regulation policy in the process of industrial structure upgrading: Evidence from Chinese provincial panel data. Sci Total Environ 753 : 142004

Zhang GX, Zhang PD, Zhang ZG, Li JX (2019) Impact of environmental regulations on industrial structure upgrading: An empirical study on Beijing-Tianjin-Hebei region in China. J Clean Prod 238: 117848

Zhao X, Liu C, Yang, M (2018) The effects of environmental regulation on China's total factor productivity: an empirical study of carbon-intensive industries. J Clean Prod 179: 325-334

Zhou Y, Zhu SJ, He CF (2017) How do environmental regulations affect industrial dynamics? Evidence from China's pollution-intensive industries. Habit Intern 60: 10-18

Zhu BZ, Zhang MF, Zhou YH, Wang P, Sheng JC, He KJ, Wei YM, Xie R (2019) Exploring the effect of industrial structure adjustment on interprovincial green development efficiency in China: a novel integrated approach. Energy Policy 134:110946 
Figures

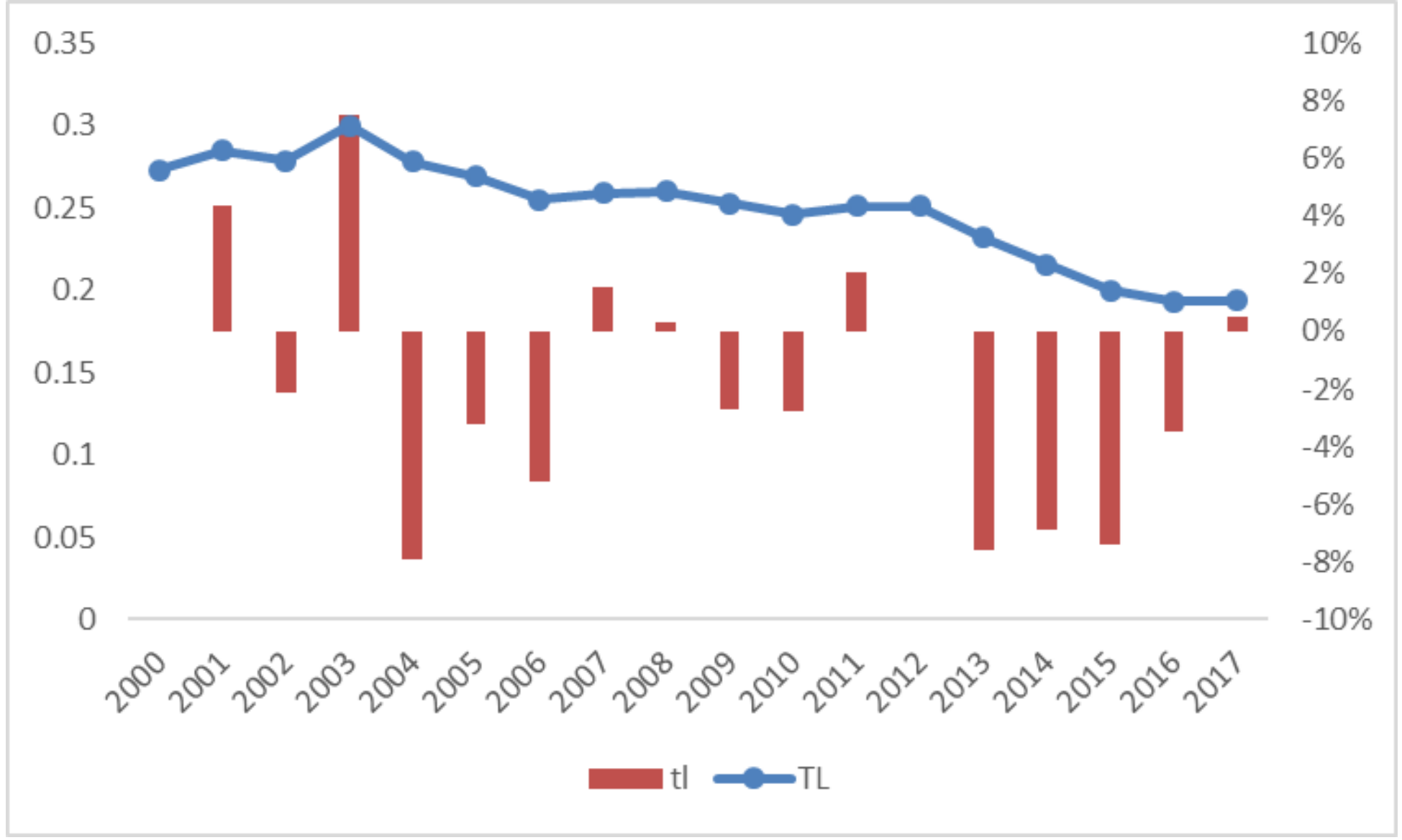

Figure 1

The average Theil index and its change range from 2000 to 2017 Note: $t \mathrm{l}$ is the range of changes in the rationalization of the industrial structure. TL is the Theil Index. 


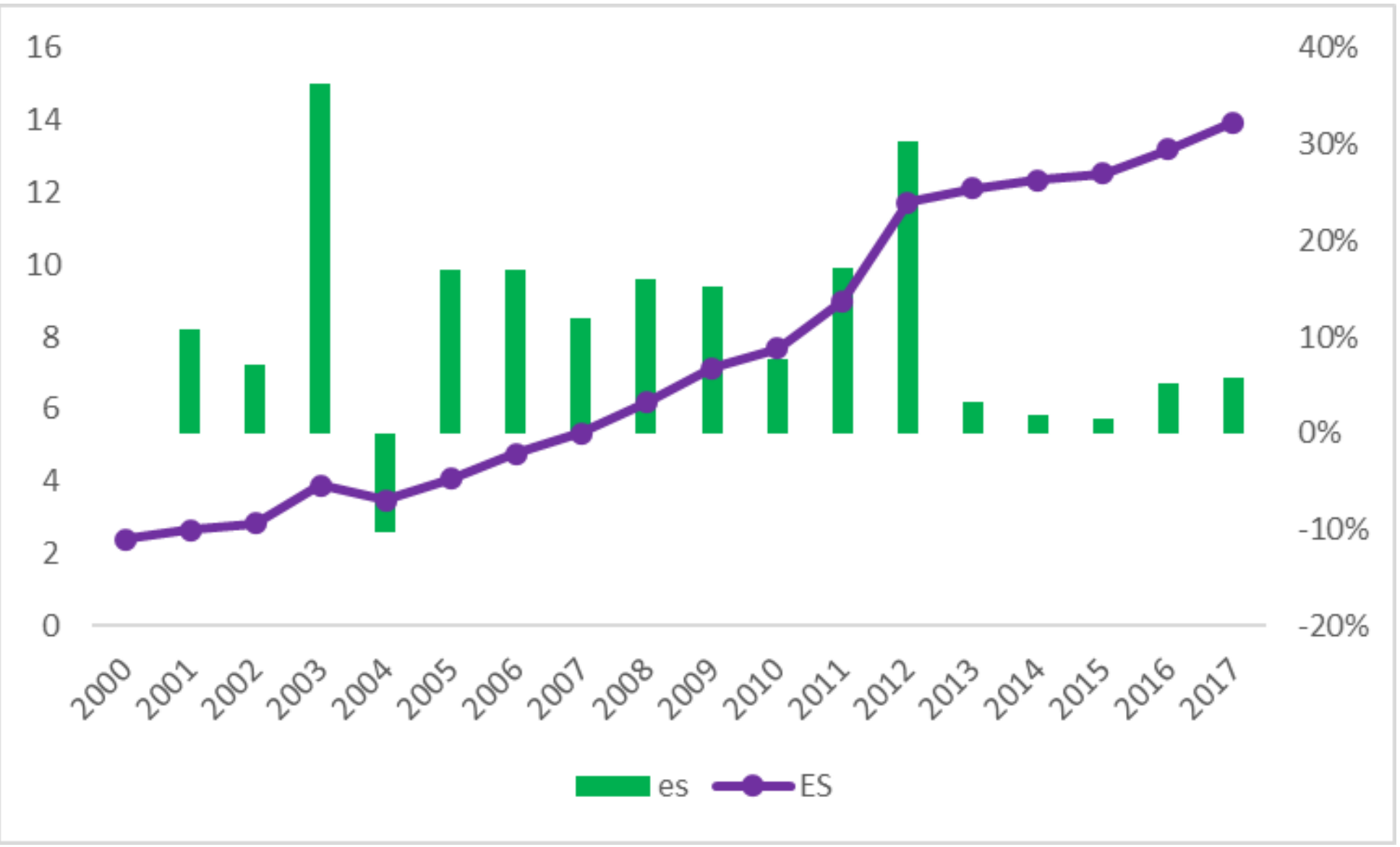

Figure 2

Average industrial structure advancement and its change range from 2000 to 2017 Note: es is the range of changes in the advanced industrial structure; ES is the advanced industrial structure. 